\title{
La música en la evolución y desarrollo de la humanidad
}

\author{
Víctor Saybay Zorogastúa \\ victor.saybay @gmail.com \\ Investigador musical
}

\author{
La música es tan antigua como la humanidad y \\ sus origenes deben buscarse en el cuerpo humano y en \\ estrecha relación con el origen de la danza.
}

\section{RESUMEN}

La música en la evolución y desarrollo de la humanidad, es un artículo que sintetiza y pretende explicar bajo los cánones científicos, filosóficos y humanísticos, el enfoque de esta organización sonora que la defino como ciencia, arte y tiempo en el contexto del desarrollo de nuestra civilización y la del propio universo.

Palabras clave: Evolución, ciencia, arte, tiempo, sonido.

\section{Music is the evolution and development of the human race}

\begin{abstract}
The music is the evolution and the development of the human race, It is an article that encapsulates and pretends to explain through scientific, philosophical and humanistic canones, the focus of this resounding organization that defines as a science, art and time in the context of civilization and the development of our own universe.
\end{abstract}

KeYwords: Evolution, science, art, time, sound. 


\section{Introducción}

La música es una organización sonora que está por encima de la luz y los estímulos visuales. El ser humano ha transcurrido su existencia inmersa en este complejo y natural universo de sonidos que nos envuelve desde el momento en que hemos sido procreados hasta el fin de nuestros días.

Este fenómeno denominado "acústica» a través de la onda hertziana va a influir de manera determinante velis nolis en nuestra formación biológica, genética, espiritual psicológica y en muchos casos, determinar las características de nuestra personalidad y el nivel de desarrollo cognitivo.

En los albores de la humanidad, el hombre fascinado por ese «mágico mundo de los sonidos», que lo envolvía, utilizó su voz, cuerpo, pies y manos para emitir sonido de respuesta y protegerse de esta manera de esta incomprensible sonoridad, convirtiéndose así mismo en un instrumento musical viviente en permanente evolución. No existe duda de que los primeros objetos sonoros que utilizó el hombre estuvieron íntimamente ligados a su cuerpo (cinturones, delantales sonoros, collares de conchas o de cáscaras duras, brazaletes para brazos y tobillos, rodilleras, etc.), al igual que las actuales tribus africanas. Todos estos objetos producían al mismo tiempo que el cuerpo estuviera en movimiento; igualmente, el hombre descubrió que algunos de sus utensilios y armas al ser golpeadas, frotadas, pulsadas, o sopladas en su interior producían sonidos variados. El siguiente paso fue dejar de adoptar estos utensilios y comenzó a fabricar estos instrumentos lo que desembocó en su construcción lo que a su vez nos muestra que había adquirido una TEKBNÉ, cierto estado de evolución mental, un principio de conocimiento. Si la presencia de una pintura prehistórica de un instrumento musical es algo turbador, «aún más conmovedor» como dice José Ortega y Gasset (1962), esta misteriosa perduración, cuando lo que pervive no es solo el encanto artístico de una imagen, sino que, como el caso presente, subsiste la realidad misma que la pintura prefiera»... ¡había nacido el arte!

\section{La música como ciencia y tiempo}

El concepto ciencia es muy amplio en su definición. Es la rama del saber humano constituida por el conjunto de conocimientos objetivos y verificables sobre una materia determinada que son obtenidos mediante la observación y la experimentación. También se define como nombre genérico de las distintas ramas del saber humano en especial la que tiene el mundo natural físico o la tecnología como materia de estudio.

Bajo estos conceptos la música es una ciencia porque en su configuración están contenidos todos estos requisitos, todas las disciplinas que el hombre ha creado a través 
de su evolución y desarrollo como especie. En ellas se encuentran inmersas las matemáticas, física, química, biología, fisiología, antropología, filosofía, etc. Y también todas las ramas del saber que se ocupan de la evolución de la tierra en el contexto del origen del universo.

Cuando nos referimos al sonido, nos involucramos en ese arte sementado en las vibraciones del aire hertziana. Las ondas hertzianas son ondas electromagnéticas con una frecuencia aproximada de 30 megavatios por segundo para ondas cortas y 150 kilociclos por segundo para ondas largas (Heinrich Hertz, 1857-1894, Alemania). Como tal, sus efectos en la formación y constitución fisiológica en los seres vivos son determinante en sus incidencias tempranas en el desarrollo formativo biológico, antropológico, intelectual, cultural, sociológico, espiritual y psicológico de todo lo que conlleva la evolución de las especies vivas.

Los físicos manifiestan que el sonido es un movimiento ondulatorio de la materia que afecta nuestro órgano auditivo por tanto es el hecho psicofisiológico, determinado por unas vibraciones cuya altura e intensidad se adaptan a las posibilidades de captación de nuestro oído las cualidades del sonido son: altura, intensidad, timbre y duración.

En la antigüedad, Pitágoras (569-470 a.C.) y Terprando (siglo VIII a. C.) en Grecia, Zarlino (1517-1590) y Galileo (1563-1642) en Italia, durante el Renacimiento, entre otros representantes de esta época, estudiaron las vinculaciones entre sonido de diversa altura, y descubrieron qué determinado número de vibraciones por segundo (frecuencia) dan un sonido que a medida que se aumenta la frecuencia, el sonido es más agudo y a la inversa, que la disminución de la frecuencia produce los sonidos graves.

Los especialistas concuerdan que el oído humano puede captar normalmente el sonido producido entre 30 y 20 mil vibraciones por segundo; pero, si el fenómeno vibratorio no alcanza los 30 ciclos por segundo, perseguimos solo un rumor confuso (infrasonido) en cambio el sonido producido por encima de los 20 mil ciclos por segundo (ultrasonido) solo es percibido por oídos muy educados o sensibles, sin embargo, estos pueden ser captados por los animales (por ejemplo, el perro).

En este inicial contacto con el sonido hemos descubierto que su primera característica, la altura, la cual viene determinada por el número de vibraciones por segundo. Es importante señalar que, en base a las relaciones de altura de los sonidos, se han organizado y estructurado la mayoría de los sistemas musicales conocidos, por ejemplo, voces de tenor, barítono, bajo, soprano, contralto, escalas musicales, etc.

La siguiente característica del sonido es el timbre. Este ingrediente nos permite distinguir entre dos o más sonidos el agente (voz o instrumento) que los produce. Gracias a la diversidad de timbre distinguimos si un sonido es producido por el piano, violín, chelo, flauta, etc.

Afirmamos que cada uno de ellos, tiene una sonoridad distinta pero lo que realmente lo hace diferente entre si es el timbre. 
La altura del sonido depende de la rapidez de las vibraciones, en cambio el timbre es generado por la riqueza de armónicos, o sonidos secundarios (llamados también parciales) que acompañan al sonido fundamental.

Hasta el siglo XVIII el timbre no tenía ninguna importancia en las creaciones musicales. Actualmente muchos compositores basan sus obras en la diversidad tímbrica de los instrumentos y voces.

El tercer componente del sonido es la intensidad que está determinada por la fuerza de vibración y medida por la amplitud de esta. Los compositores clásicos conocieron la importancia de la intensidad, pero su utilización sistemática como factor sustancial es reciente. El sonido abstracto de altura, timbre e intensidad no se "concreta", es decir no se produce hasta que «entra en el tiempo», o sea ha de nacer y tener cierta vigencia temporal.

En materia de duración ocurre que un sonido para ser captado debe tener una duración superior a una centésima de segundo. Por debajo de esta brevísima vigencia solo captamos un clip sin altura definida. Entonces nos encontramos con la cuarta característica del sonido: la duración. Este factor conjugado con la altura interviene siempre en la estructuración de los sistemas musicales debido a que de la duración del sonido, depende en gran parte el nacimiento del ritmo, elemento básico y esencial en el concepto de música.

Habiendo definido claramente los cuatro elementos y básicos que comprenden el sonido, podemos tener una clara idea de los efectos que produce el sonido musical en el desarrollo cognitivo, fisiológico y neurológico del ser humano.

La neuropsicología, ha destacado con múltiples investigaciones que relacionan los sonidos y melodías a determinados estímulos cerebrales por lo mismo que aprender música se asocia al desarrollo de habilidades y destrezas que permiten adquirir conocimientos como idiomas y matemáticas, entre otras disciplinas abstractas. Pero aún existe la idea, de que solo ciertas personas tienen condiciones especiales para aprenderla lo que limita su aprendizaje, indica Carlos Miro, doctor en Ciencias Musicales del Instituto de Musicología de la Academia de Ciencia de Hungría. Estudios modernos han comprobado que el cerebro se convierte en un todo movimiento como una fiesta de luces. Cuando es estimulado con la música adecuada, todo su sistema neurológico central y periférico entra en actividad generando una serie de elementos químicos a través de sus neuronas (Hipócrates, 400 a.C., estudió la función cognitiva y sostuvo que el cerebro era la sede de la inteligencia que permitió el nacimiento y el estudio de la neurociencia).

La música afecta directamente a las neuronas sensoriales (del griego neuron: 'cuerda, nervio') las cuales envían información de los receptores sensoriales al sistema nervioso central (SNC). Todo este sistema central y periférico recibe esta información acústica en forma permanente, produciendo una serie de efectos fisiológicos y determinando ciertos resultados genéticos y patológicos. 
Las neuronas están compuestas por un cuerpo celular y unas prolongaciones llamadas axones y dendritas. Estas últimas son unos delgados hilos nerviosos que se comunican con nuestros órganos internos (corazón, páncreas, hígado, etc.).

Son las neuronas del oído las que poseen las dendritas más largas de nuestro organismo y se comunican directamente con estos de allí que el sonido nos afecta directamente al ingresar por el oído. La fisiología (Physis 'naturaleza' y logos 'conocimiento, estudio'). La fisiología es una de las ciencias antigua del mundo y estudia las funciones de los seres multicelulares.

Las ondas hertzianas afectan directamente a nuestros órganos internos, en este caso la intensidad, va a jugar un rol importante en el comportamiento psicológico, social, intelectual del individuo y en muchos casos determinar una patología (brazo de la ciencia médica, referente a la causa, origen y naturaleza de la enfermedad). Es el sistema nervioso central y periférico el más afectado cuando la altura, intensidad y duración de los sonidos no guardan las proporciones adecuadas en los rangos sonoros (antes explicados) que el ser humano puede soportar (caso de parlantes con sonidos estridentes, como ruidos de fuerte intensidad, sonidos agudos y graves por encima de los decibeles permitidos). Las monotonías rítmicas y melódicas determinan una personalidad disociativa, según estudios psicológicos recientes.

Profundos estudios neurológicos y fisiológicos han demostrado que a través de una «musicoterapia adecuada» desde la etapa prenatal, el ser humano desarrollo cualidades cognitivas por encima de los rangos normales. Alfred Tomatis (Francia, 1920-2001), en la década de los 60 en el mundo, evolucionó la música en el mundo occidental con su aplicación de estos conceptos de los seres humanos desde la etapa prenatal.

La historia de la música no es sino la de un proceso selectivo (il faut choisior, decía Pascal) de vibraciones audibles, o sea de sonidos encaminados a obtener una superior precisión en la emisión sonora de unas «alturas escogidas como fundamentales» (que son los grados de la escala musical, más familiarmente conocido con el nombre de notas).

Las magnitudes físicas fundamentales y derivadas son aquellas que permiten expresar cualquier cantidad y medición de los cuerpos con kilogramos, metro, segundo, etc. La música en este contexto científico la música cuenta con una magnitud física fundamental, porque su unidad de medida es el segundo, el que a su vez se representa en el alfabeto musical con una negra (figura de duración que dura un tiempo, ósea un segundo). Para su aplicación la música cuenta con un reloj especial llamado metrónomo (del griego métron 'medida' y nomos 'ley, norma') aparato utilizado para indicar el tiempo o pulso de las composiciones musicales que puede controlarse su velocidad a capricho del músico.

La presencia de la disciplina como la matemáticas, física, química, etc., en el idioma musical, son innegables en mi obra el Mágico mundo de los sonidos, la música idioma uni- 
versal de la humanidad profundizo más detalladamente sobre los números 2, 3 y 4 que son los numerados de los indicadores de comas, asimismo, el número mágico 3 que es la cifra que se utiliza para producir todos los indicadores de los compases compuestos, el numerador 5 también es abordado en esta obra ya que es un número importante que representa el compás de amalgama. Este dígito tiene una relevancia muy importante en las matemática y física, representa al número áureo, presente en todas las grandes obras arquitectónicas, plásticas, y sonoras de nuestra civilización, representa la perfección de la belleza, la que se ve diariamente en el cosmos. Asimismo, la espiral de las octavas también encuentra su explicación en el número áureo esa constante y reiterada sucesión de círculos de do a do. La presencia de las secuencias Fibonacci, nos da explicaciones muy severas y profundas a este fenómeno científico, que no deja de asombrarnos (Leonardo Pisano Bigollo o comúnmente Fibonocci, 1170, Pisa-Italia, matemático italiano que difundió en Europa la utilidad práctica del sistema de numeración indo-arábiga, más conocida como frecuencia Fibonocci, frente a la numeración romana).

\section{El arte musical}

Los orígenes de la música, en su concepto como arte musical, este cimentado en las vibraciones del aire, es decir en ese algo etéreo e inaprensible, imposible de comprender o captar, por ser demasiado sutil, es aquello que no vemos y denominamos sonido que es la materia prima con la que se han creado las grandes obras musicales. El estudio del sonido como fenómeno físico, es tan antiguo como el desarrollo de las civilizaciones que poblaron la Tierra. Pero el análisis de la naturaleza como arte es producto de nuestra sociedad.

Hablar de arte musical es sinónimo de belleza, la cual en su definición es significado de estética (rama de la filosofía que analiza este concepto) hermosura y que la sociedad en general considera como atractiva deseable y bonitas.

No olvidar que la belleza produce un placer que proviene de las manifestaciones sensoriales y que puede sentirse por la vista (por ejemplo, una persona que puede ser atractiva) o el oído (al escuchar una voz o una música agradable). Unos de los cánones de belleza más extendida es la armonía. Los seres humanos tienden a considerar que la armonía y las proporciones adecuadas son deseables. Teniendo como preceptos estos análisis y apreciaciones podemos colegir y afirmar que «la música es arte» y que está íntimamente ligada al concepto de belleza-armonía y equilibrio, en todas las formas en que se manifiesta.

El mundo sonoro musical necesita cumplir con estos preceptos para entrelazar y construir esa pirámide de sonido y lograr de esta manera llegar al objetivo de la belleza sonora que conmueva y deleite al oyente. 
Manuel Valls Gorina, en su obra Aproximación a la música sostiene que las muestras más antiguas de instrumentos musicales creadas por el hombre datan de hace 40 mil años a. C. En plena era del paleolítico superior, el hombre de Cro-magnon vivía en las cavernas de la capital prehistórica de la humanidad: Francia, donde en la Gruta De Los Tres Hermanos en Ariége, se observa un enmascarado con un marco musical, conduce una manada de renos. Este arco musical es usado en la actualidad por diversas tribus precolombinas en la selva de Honduras, seńalando que este es el antecesor de todos los instrumentos de cuerda de la actualidad. Se han encontrado yacimientos prehistóricos con flautas rectas construidas de huesos que datan de hace 25 mil años a. C.

Después de haber viajado en el tiempo y habernos maravillado increíblemente en el mundo de la música, construido en base a las vibraciones del aire esa organización sonora de sonidos abstractos, perduraran eternamente en toda humanidad, al igual que todas las majestuosas obras de los grandes maestros de la música como: Beethoven, Mozart, Vivaldi, Bach, etc., con sus maravillosas composiciones que nacieron del pueblo que es el origen del arte.

\section{Referencias}

Antón, L. (1999). Fundamentos del aprendizaje significativo. Lima: Editorial San Marcos, Colección Biblioteca Pedagógica.

Darwing, C. (1809). Orígenes del Hombre.

De Pisa, L. (1170). Secuencia Fibonacci. Italia.

De Rubertis, V. Teoría de la música.

Enciclopedia de la Música (1948). Editorial Atlante S.A México, DF. W.M. Jackson - Inc Editores.

Instituto Parramón (1954). Instrumentos musicales. Ediciones S.A: Barcelona, España

Miró, C. (2010). Técnicas de la liberación emocional y didácticas aplicadas a la educación musical. Instituto de Musicología de la Academia de Ciencia de Hungría: Universidad Andrés Bello. Ortega y Gasset, J. (1962). Abejas milenarias. Madrid: Editorial Revista de Occidente.

Saybay, V. (2010). Importancia de la música en el desarrollo del intelecto humano. Extracto de la Conferencia Ofrecida en el Congreso de Pedagogía. Derrama Magisterial: Piura, Perú.

Saybay, V. (2014). Razonamiento lógico musical. Seminario del Colegio Nacional de Músicos del Perú. Chosica, Perú.

Saybay, V. (2015). El mágico mundo de los sonidos: La música idioma universal de la humanidad. Editorial Música y Arte: Perú.

Tesla, N. Mapa matemático de Tesla - Los números mágicos 3, 6 y 9.

Tesla, N. El número áureo.

Valls, M. (1970). Aproximación a la música. Salvat Editoras S. A. y Alianza Editorial S. A. 